\title{
TERMINAÇÃO DE CORDEIROS, COM E SEM SUPLEMENTAÇÃO NA FASE DE CRIA, CONFINADOS OU SEMICONFINADOS EM Brachiaria brizantha DIFERIDA: PARASITISMO GASTRINTESTINAL E EFICIÊNCIA BIOECONÔMICA
}

\section{PERFORMANCE OF CREEP FEED LAMBS, FINISHED UNDER FEEDLOT OR Brachiaria brizantha DEFERRED PASTURE: GASTRINTESTINAL PARASITISM AND BIOECONOMIC EFFICIENCY}

\author{
João Batista Catto ${ }^{1^{*}}$ ORCID - http://orcid.org/0000-0001-7013-4870 \\ Fernando Alvarenga Reis ${ }^{2}$ ORCID - http://orcid.org/0000-0002-9903-3384 \\ Gelson Luis Dias Feijo ${ }^{1}$ ORCID - http://orcid.org/0000-0003-0278-1755 \\ Fernando Paim Costa ${ }^{1}$ ORCID - http://orcid.org/0000-0002-8581-9212 \\ Jose Alexandre Agiova da Costa² ORCID - http://orcid.org/0000-0003-4850-5203 \\ Luis Henrique Fernandes ${ }^{1}$ ORCID - http://orcid.org/0000-0002-9369-1028 \\ Nilton Gabriel Paiva Guimarães ${ }^{1}$ ORCID - http://orcid.org/0000-0002-3531-6158 \\ ${ }^{1}$ Centro Nacional de Pesquisa em Gado de Corte, EMBRAPA, Campo Grande, MS, Brasil. \\ ${ }^{2}$ Centro Nacional de Pesquisa em Caprinos e Ovinos, EMBRAPA, Sobral, CE, Brasil. \\ *Autor para correspondência - joao.catto@embrapa.br
}

\section{Resumo}

Objetivou-se avaliar os efeitos da suplementação na fase de aleitamento sobre o desempenho ponderal, o grau de infecção por nematódeos gastrintestinais e a viabilidade econômica na terminação de cordeiros em confinamento ou semiconfinamento. Na fase de aleitamento, os cordeiros de seis lotes de 30 ovelhas foram pesados ao nascimento e ao desmame. Três lotes foram suplementados em cochos individuais e o consumo de alimento foi mensurado. Na segunda fase, pós-desmame, os cordeiros foram distribuídos em dois grupos, considerando sexo, peso ao desmame e suplementação durante o aleitamento, para terminação em confinamento ou semiconfinamento. Todos os animais foram everminados no início da terminação. Os animais foram pesados a cada 14 dias e arraçoados com concentrado na proporção de $2 \%$ do peso vivo. Os animais confinados receberam silagem de sorgo, e os semiconfinados foram mantidos em pastagem de Braquiaria brizantha cv Piatã. A suplementação na fase de cria teve efeito no peso e no ganho em peso na desmama e na terminação, mas com retorno econômico favorável somente na terminação. O diferimento do pasto no sistema de semiconfinamento controlou a verminose, evitando mortes, e não houve diferenças no peso e no ganho em peso entre os cordeiros confinados ou semiconfinados. Os dois sistemas foram viáveis, mas o lucro no semiconfinamento foi 2,3 vezes superior ao do confinamento.

Palavras-chave: suplementação privativa, cordeiro pantaneiro, nematódeos, ganho de peso, sistema de terminação.

\footnotetext{
Abstract

The objectives of this study were to evaluate the effect of creep feeding and drylots or semi confined raised lambs on weight gain, gastrointestinal nematodes infection and economic viability. Lambs
} 
from six lots of 30 ewes were weighed at birth and at weaning and the offspring of three lots were supplemented in private troughs and their food intake was measured. In the second phase, after weaning, lambs were divided into two finishing groups, feedlot or semi confinement considering gender, weaning weight and creep feeding. All animals were dewormed at early termination, weighed every 14 days and supplemented with $2 \%$ of body weight. Feedlot animals received sorghum silage while semi confined animals were kept at pasture on Brachiaria brizantha cv Piata. Creep feeding had effect on weight and weight gain at weaning and finishing, but favorable economic returns were only observed at termination. Pasture deferred in the semi-confinement system controlled verminosis, preventing deaths with no differences in weight and weight gain among feedlots or semi-confined lambs. Both systems were economically viable, but profit in semi confinement was 2.3 times higher than the feedlots.

Keywords: creep feeding, drylots, lambs, nematodes, finishing systems.

Recebido em: 03 de junho de 2016

Aceito em: 20 de dezembro de 2018

\section{Introdução}

A produção de carne ovina no Brasil, estimulada pelo aumento do consumo, está se expandindo para estados, de menor tradição em ovinocultura, das regiões Sudeste e Centro-Oeste. ${ }^{(1)}$ No aspecto sanitário, a verminose é o principal entrave no sistema produtivo. A infecção pelos nematódeos gastrintestinais em ovinos é problema, principalmente, nos animais jovens que ainda não desenvolveram imunidade $^{(2)}$. Em ovinos sob pastejo, a infecção parasitária reduziu de $20 \%$ a $60 \%$ o ganho em peso e causou mortalidade entre $20 \%$ e $40 \%$ no Rio Grande do Sul, ${ }^{(3)}$ provocando mortalidade de $16,1 \%$ na recria de cordeiros no estado de São Paulo. ${ }^{(4)}$ Haemonchus contortus, devido à elevada prevalência, alta patogenicidade e capacidade de se tornar resistente às principais bases de anti-helmínticos (AHs) representa, atualmente, a maior ameaça parasitária à ovinocultura nacional. ${ }^{(5-}$ 6)

$\mathrm{O}$ uso incorreto e frequente dos $\mathrm{AHs}$ tem levado à seleção de populações resistentes em todas as regiões do Brasil. No Mato Grosso do Sul, a maioria dos rebanhos de ovinos mostraram resistência múltipla a seis moléculas pertencentes a cinco classes de AHs com índices de resistência mais elevados para as espécies Haemonchus contortus e Trichostrongylus colubriformis. ${ }^{(7)}$

Para evitar reduções no ganho em peso e na mortalidade elevada causada pela verminose, tem-se utilizado a prática da mamada controlada na fase de cria (cordeiros confinados desde o nascimento até o desmame) e/ou o confinamento na terminação, aumentando os custos com instalações, mão de obra e alimentação. ${ }^{(2)}$ Diversos estudos sobre manejo de pastagem têm sido realizados com o objetivo de minimizar o efeito das verminoses na recria e/ou na terminação de cordeiros, abordando pastejo rotacionado ou pastejo simultâneo com outras espécies de herbívoros. ${ }^{(8)}$ O pastejo rotacionado é referido como uma forma de diminuir as populações de larvas de nematódeos, contudo, se o período de descanso da pastagem não for suficiente, pode exacerbar o problema da verminose, já que as larvas infectantes podem sobreviver meses no ambiente. ${ }^{(9-10)}$ Por essa razão, o pastejo rotacionado pode resultar justamente no contrário do que se esperaria em termos de descontaminação do ambiente. ${ }^{(8)}$

Em Mato Grosso do Sul, a cadeia da carne de ovinos, ainda em formação, caracteriza-se pelo caráter familiar dos sistemas produtivos, com baixo nível de investimento e número pequeno de animais. Nesse contexto, a alternativa de terminação em confinamento, tecnicamente interessante, aumenta o 
risco da atividade, dado o maior custo com infraestrutura, produção de alimentos e mão de obra.

Objetivou-se com este estudo avaliar o desempenho físico e econômico de cordeiros, com ou sem suplementação privativa durante a fase de aleitamento, terminados em confinamento ou em semiconfinamento em pastagem de Brachiaria brizantha diferida, bem como o grau de parasitismo por nematódeos gastrintestinais e suas consequências no ganho de peso

\section{Material e métodos}

O experimento foi conduzido em dois ciclos reprodutivos na Fazenda Modelo da Embrapa Gado de Corte (CNPGC), no município de Terenos, Mato Grosso do Sul (coordenadas: 20³3'S; 544ㅇ' $\mathrm{O}$ $521 \mathrm{~m}$ de altitude). No primeiro ano, utilizaram-se 99 cordeiros (44 machos e 55 fềmeas) nascidos entre 28/03/2011 e 25/04/2011; no segundo ano, foram 105 cordeiros (47 machos e 58 fêmeas) nascidos entre 03/05/2012 e 06/06/2012. Em cada ciclo, os cordeiros eram oriundos de seis grupos de 30 ovelhas mantidas em piquetes contíguos de Brachiaria brizantha cv Marandu. Os cordeiros de três desses grupos foram submetidos, a partir dos 15 dias de idade, à alimentação privativa à vontade ofertada pela manhã e à tarde. O concentrado oferecido continha $18 \%$ de proteína bruta, composto de milho (43,67\%), farelo de soja (10,33\%), farelo de trigo $(20,00 \%)$, casquinha de soja $(20,00 \%)$, sal mineral $(3,43 \%)$, Amireia $180(2,5 \%)$, vitamina $\operatorname{ADE}(0,05 \%)$ e monensina sódica $(0,02 \%)$. No desmame, em 21/06/2011 e 08/08/2012, os cordeiros foram divididos em dois grupos balanceados para sexo, peso ao desmame e recebimento (CSP) ou não (SSP) de alimentação privativa na fase de aleitamento.

O grupo semiconfinado foi alocado em pastagem de 1,2 ha de Brachiaria brizantha cv Piatã, diferida 150 dias antes do desmame (período estabelecido para eliminação da contaminação por larvas infectantes dos nematódeos). Para controlar a altura e diminuir a perda de qualidade do pasto, devido ao longo período de veda, a área foi esporadicamente pastejada por vacas multíparas secas, sendo novamente diferida por 60 dias antes do desmame dos cordeiros. No primeiro ano, fez-se correção do solo, com 1,5 tonelada de calcário/ha e $400 \mathrm{~kg} / \mathrm{ha}$ da fórmula 4:30:10. No segundo ano, não houve adubação e a área foi subdividida em duas para pastejo alternado. Foram realizadas amostragens da pastagem para determinação da matéria seca disponível no início e no final da terminação e em duas ocasiões intermediárias.

O grupo confinado foi subdividido em lotes de 10 animais, homogêneos para peso vivo e sexo, que foram colocados em baias cobertas e receberam silagem de sorgo (PB 9,5\%, FDN 52,8\%, FDA $35,5 \%$ ) à vontade, ofertada pela manhã e à tarde com regulagem pela sobra diária.

Ambos os grupos, confinado e semiconfinado, foram suplementados na proporção de $2 \%$ do peso vivo com ração elaborada para um ganho estimado de $200 \mathrm{~g} /$ dia. O suplemento ofertado, composto por farelo de soja (9,98\%), milho grão seco (83,78\%), sal mineral $(4,75 \%)$, sulfato de amônia $(0,14 \%)$ e ureia (1,35\%), apresentava $17 \%$ de PB e $85,2 \%$ de NDT e era ofertado pela manhã e à tarde.

Os animais foram pesados ao nascimento, 14 dias antes do desmame e no desmame. Os desmames foram aos 73,2 \pm 8,6 dias, no primeiro ciclo, e aos 81,6 \pm 8,7 dias no segundo ciclo experimental. Após o desmame, os animais foram pesados a cada 14 dias para correção da quantidade de concentrado a ser ofertado. Por ocasião das pesagens, foram realizadas coletas de fezes para exames de OPG, segundo Gordon \& Whitlock, ${ }^{(11)}$ e identificação de larvas infectantes, segundo Keith. ${ }^{(12)}$ Todos os cordeiros foram everminados duas semanas antes do desmame com trichorflon e, no 
desmame, com levamisol e closantel.

Os dados de desempenho animal e de OPG (transformados em log de OPG+1) foram analisados por meio de análise de variância, e as médias ajustadas foram comparadas pelo teste de Tukey ao nível de 5\% de significância. O modelo utilizado para a análise, por meio do procedimento GLM do SAS, (13) continha os efeitos fixos do sexo (macho ou fêmea), do uso do creep-feeding na fase de aleitamento (sim ou não), do tipo de parto da ovelha (simples ou gemelar), do ano de nascimento do cordeiro (1 ou 2), do tipo de terminação (confinamento ou semiconfinamento), das interações simples entre esses fatores e o peso ao nascimento como covariável.

A análise econômica do experimento compreendeu duas partes. Na primeira, avaliou-se o efeito da suplementação privativa durante o aleitamento (tratamentos CSP e SSP) e, na segunda parte, avaliaram-se as duas alternativas de terminação (confinamento e semiconfinamento).

Utilizou-se a orçamentação parcial ${ }^{(14)}$ para a avaliação do uso de creep-feeding. Para tanto, analisouse um lote de 100 animais e os custos adicionais referem-se à ração, à mão de obra, aos cochos e à estrutura para alimentação privativa. Já os ganhos adicionais referem-se ao valor do acréscimo de peso vivo obtido.

Para a análise econômica da fase de engorda dos cordeiros, foram simulados lotes de 100 animais em quatro ciclos de terminação por ano. Para a análise, foram consideradas como peso final a média dos pesos finais $(30,15 \mathrm{~kg}$ de peso vivo) e, como ganho de peso, a média dos ganhos de peso (188 g/dia) observados nos cordeiros machos que receberam suplementação privativa durante o aleitamento. No semiconfinamento, dada a necessidade de diferir o pasto por longo período e viabilizar a realização de quatro ciclos anuais, a área foi triplicada, constituindo-se de 7,2 ha de braquiária. No confinamento, a área foi de $625 \mathrm{~m}^{2}$, ocupada com baias e depósitos para silagem, sal e concentrado.

Os indicadores de desempenho econômico foram a margem bruta, a margem operacional e o lucro observados após a definição do custo operacional e do custo total por unidade de produto obtido, sendo a margem bruta resultado da receita total menos os desembolsos; a margem operacional o resultado da receita total menos o custo operacional; e o lucro o resultado da receita total menos o custo total. O custo operacional foi composto pela soma de desembolsos e depreciações. O custo total correspondeu ao custo operacional mais os custos de oportunidade do capital.

A depreciação foi calculada pelo método linear. Para o custo de oportunidade do capital, usaram-se taxas de juros variáveis segundo o grau de liquidez dos recursos empregados. Os preços foram os praticados no primeiro semestre de 2015 em Mato Grosso do Sul.

\section{Resultados e discussão}

A disponibilidade de MS do material verde (folhas) no final da terminação no primeiro ano estava em $10 \mathrm{~kg} / \mathrm{ha}$ e os animais foram suplementados com 3\% do peso vivo nos últimos 10 dias antes do abate (Figura 1). A subdivisão do piquete no segundo ano proporcionou oferta mais equilibrada de pastagem durante o período de terminação (Figura 1). No primeiro ano, a percentagem de proteína bruta na MS variou de 7,3\% a 9,1\% e, no segundo ano, variou de 4,6\% a 10,7\%. 


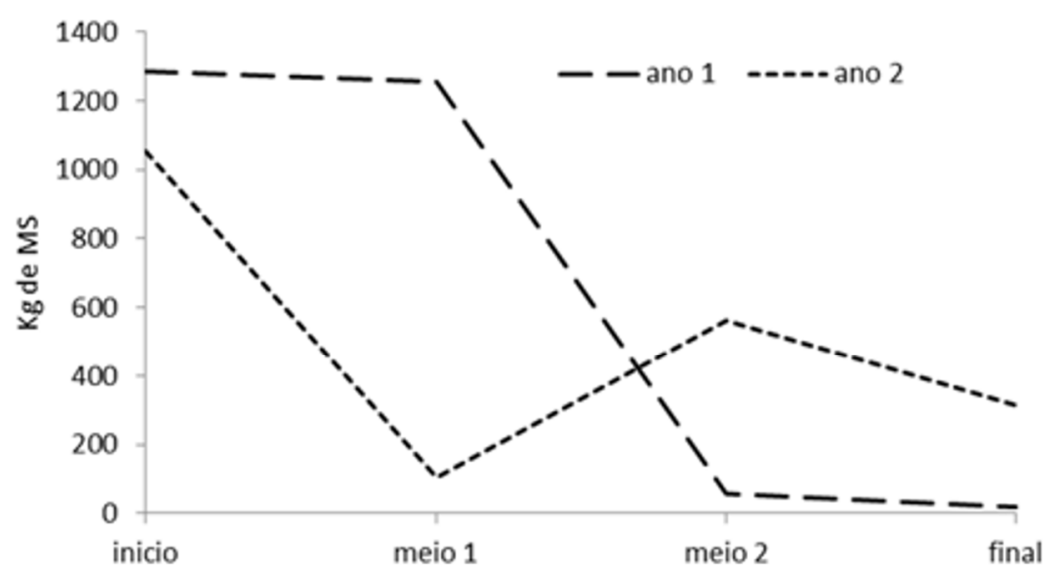

Figura 1. Disponibilidade de matéria seca (folhas) em pastagem de Brachiaria brizantha cv Piatã.

Não houve interação $(\mathrm{P}>0,05)$ entre os fatores ano, sexo, tipo de parto, creep-feeding e terminação para as variáveis de desempenho animal e OPG.

Fêmeas e machos apresentaram pesos similares $(\mathrm{P}>0,05)$ ao nascimento, $3,5 \pm 0,8 \mathrm{~kg}$ e 3,6 $00,9 \mathrm{~kg}$, respetivamente. Por outro lado, os cordeiros de partos gemelares foram mais leves $(3,2 \pm 0,2 \mathrm{~kg})$ que os de parto simples $(3,6 \pm 0,1 \mathrm{~kg})$. Já no desmame, os machos estavam mais pesados $(15,8 \pm 0,4 \mathrm{~kg})$ que as fêmeas $(14,9 \pm 0,4 \mathrm{~kg})$, mas o tipo de parto não teve efeito no peso e no ganho de peso do nascimento ao desmame (Tabela 1).

Tabela 1. Níveis de significância para tipo de parto (simples e duplo), sexo, suplementação privativa na fase de aleitamento (com e sem) e de terminação (confinados e semiconfinados) no peso e no ganho de peso de cordeiros do grupo racial Pantaneiro, no Mato Grosso do Sul

\begin{tabular}{lcccc}
\hline & tipo parto & sexo & sup. priv. & terminação \\
\hline Peso - nascimento & + & $\mathrm{ns}$ & - & - \\
Peso - desmama & $\mathrm{ns}$ & + & ++ & - \\
Ganho de peso - desmama & $\mathrm{ns}$ & + & ++ & - \\
Peso - final & $\mathrm{ns}$ & +++ & ++ & $\mathrm{ns}$ \\
Ganho peso - terminação & $\mathrm{ns}$ & +++ & ++ & $\mathrm{ns}$ \\
Ganho de peso - nasc. term. & $\mathrm{ns}$ & +++ & +++ & $\mathrm{ns}$ \\
\hline
\end{tabular}

$*<0,05 ; * *<0,01 ; * * *<0,001$

Durante a fase de aleitamento, os cordeiros suplementados consumiram, em média, $14 \mathrm{~kg}$ de concentrado/animal, aproximadamente $2,5 \%$ do peso vivo. A suplementação privativa durante o aleitamento influenciou o peso e o ganho de peso na fase de cria e na terminação (Tabela 1). No desmame, os cordeiros suplementados pesaram em média $16,4 \pm 0,4 \mathrm{~kg}$ e os não suplementados $14,3 \pm 0,4 \mathrm{~kg}$, com ganhos diários de $166 \mathrm{~g}$ e $140 \mathrm{~g}$, respectivamente. Os cordeiros suplementados durante o aleitamento terminaram com $27,6 \pm 0,6 \mathrm{~kg}$ e os não suplementados com $24,4 \pm 0,7 \mathrm{~kg}$, com ganhos no período de $11,2 \pm 0,4 \mathrm{~kg}$ e 10,1 $\pm 0,4$, e diários de $171 \mathrm{~g}$ e 153 g, respectivamente (Tabela 1 e Figura 2).

Machos e fêmeas mostraram resposta positiva à suplementação privativa. Até o desmame, as fêmeas suplementadas ganharam $1,6 \mathrm{~kg}$ a mais que as não suplementadas $(12,1 \mathrm{~kg}$ vs. $10,5 \mathrm{~kg})$ e os machos 2,6 $\mathrm{kg}(13,6 \pm 0,5 \mathrm{~kg}$ vs. $11,0 \pm 0,5 \mathrm{~kg})$. As fêmeas suplementadas terminaram com $2,7 \mathrm{~kg}$ a mais que as não suplementadas $(25,8 \pm 0,7 \mathrm{~kg}$ vs. $23,1 \pm 0,9 \mathrm{~kg})$ e os machos com $3,9 \mathrm{~kg}$ a mais $(29,5 \pm 0,8 \mathrm{vs} .25,6 \pm 0,8)$. Com os ganhos de peso diário de $188 \mathrm{~g}$ nos cordeiros suplementados no aleitamento e $167 \mathrm{~g}$ nos não suplementados observados na terminação, os cordeiros não suplementados necessitariam de mais 23 dias 
para atingirem o peso dos cordeiros suplementados. Segundo Sampaio et al., ${ }^{(17)}$ a suplementação privativa de cordeiros pode encurtar o tempo de acabamento para o abate, além de melhorar as funções reprodutivas das ovelhas. Entretanto, são escassos os trabalhos sobre o efeito da suplementação privativa até o desmame como alternativa de terminação de cordeiros em pasto ou em confinamento.

Um efeito expressivo da suplementação para aumentar o ganho de peso foi observado em cordeiros $3 / 4$ mestiços Suffolk suplementados e mantidos em grama estrela branca (Cynodon plectostachyus). ${ }^{(18)}$ Animais suplementados apresentaram um ganho de $147 \mathrm{~g} /$ dia superior a animais não suplementados e, como neste estudo, os machos ganharam mais peso do que as fêmeas.

Diferentemente, Silveira et al. ${ }^{(19)}$ não observaram efeito da suplementação em cordeiros Suffolk, em pastagem de azevém quando suplementados a partir dos 40 dias de idade, na base de $1 \%$ do peso vivo. De forma similar, Poli et al. ${ }^{(20)}$ também não encontraram efeito da suplementação em cordeiros Suffolk em pastagem de Tifton 85 sobressemeada com azevém e suplementados a partir dos 60 dias de idade. Segundo os autores, a composição química, a adequada disponibilidade dos pastos utilizados, a quantidade insuficiente de concentrado fornecido e o início tardio da suplementação podem ter sido as causas para a não obtenção de efeito. Neste estudo, os cordeiros foram mantidos em pastagem de braquiária com menor valor nutritivo, a suplementação foi iniciada nos primeiros dias de vida e o consumo foi de aproximadamente $2,5 \%$ do peso vivo/dia.

A forma de terminação não teve efeito no peso e no ganho de peso dos animais. Os cordeiros confinados

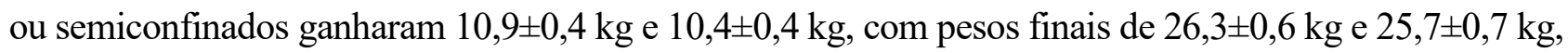
respectivamente (Tabela 1, Figura 2), e com ganhos médios diários de $145 \mathrm{~g}$ para as fêmeas e $177 \mathrm{~g}$ para os machos. Os ganhos de peso são próximos aos 142 a $162 \mathrm{~g} /$ dia observados em animais do mesmo grupamento racial terminados em confinamento ${ }^{(21-22)}$ e superiores aos $128 \mathrm{~g} / \mathrm{dia}$ em cordeiros mestiços Santa Inês X Pantaneiro em pastagem de Brachiaria brizantha cv Marandu suplementados com 2\% do peso vivo. ${ }^{(23)}$

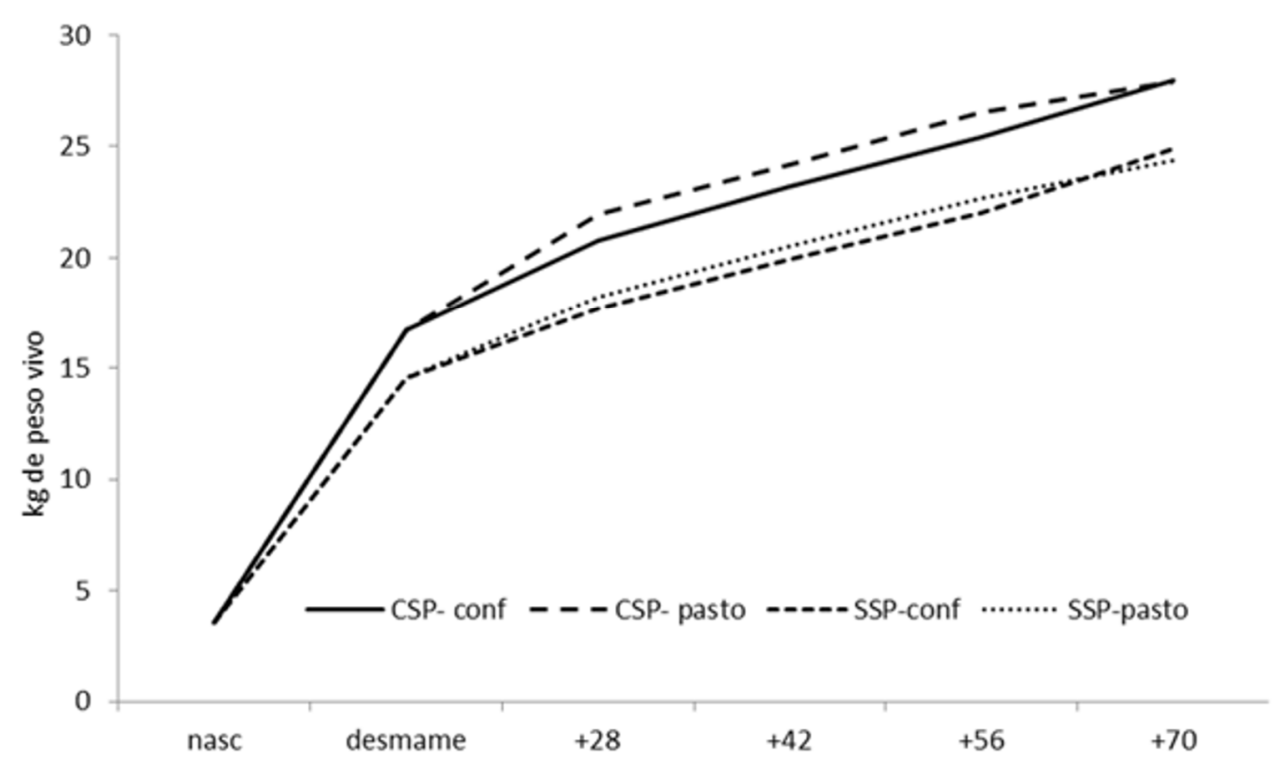

Figura 2. Peso médio de cordeiro(a)s do nascimento até terminação, suplementados (CSP) ou não (SSP) em cochos privativos na fase de cria e terminados em confinamento (conf) ou semiconfinamento (pasto). 
A produção de ovinos exclusivamente em pastagem predomina em regiões temperadas, onde se obtém adequada produção de pastagem de boa qualidade durante praticamente todo o ano. ${ }^{(24)}$ Nessas condições, cordeiros terminados em pastagem de alfafa ganharam peso e mostraram características de carcaça semelhantes aos animais confinados. ${ }^{(25)}$ No Rio Grande do Sul, cordeiros Ile de France $\mathrm{x}$ Texel ganharam $404 \mathrm{~g} /$ dia quando terminados em pastagem de azevém recém-implantada, $325 \mathrm{~g} /$ dia em pastagem natural recebendo $2 \%$ de suplementação proteica e $213 \mathrm{~g} /$ dia quando confinados, recebendo silagem de sorgo e a mesma suplementação proteica. ${ }^{(24)}$

Em regiões de clima quente e distribuição irregular das chuvas, com variação sazonal na disponibilidade e na qualidade das pastagens, e onde a hemoncose é o maior desafio sanitário, a alternativa de confinar tem sido recomendada apesar do custo de produção mais elevado. $\mathrm{O}$ confinamento permite eliminar a verminose, aumentar a taxa de lotação da propriedade, melhorar as condições alimentares do rebanho e disponibilizar carne ovina de melhor qualidade, inclusive na entressafra. ${ }^{(26)}$ Entretanto, apesar das melhorias no desempenho animal, o confinamento aumenta muito os investimentos em alimentação, mão de obra e instalações, podendo tornar o sistema economicamente inviável. ${ }^{(27)}$

Por outro lado, cordeiros terminados em pastagem, quando comparados com animais confinados, apresentaram produtividade baixa determinada pela taxa de mortalidade alta $(16,2 \%)$ e ganho de peso muito inferior causado por infecções elevadas de Haemonchus e Trichostrongylus. ${ }^{(4)}$

Cordeiros Corriedale, com peso de abate entre 30 e $32 \mathrm{~kg}$, confinados e recebendo ração completa com a mesma composição química da pastagem (Cynodon dactylon), apresentaram ganho de peso diário superior (144 g) aos terminados em pastagem (106 g) e idade de abate de 219 e 258 dias, respectivamente. ${ }^{(28)}$ Em ovinos de corte, a infecção média por vermes em animais confinados foi inferior a 500 OPG, nível estabelecido para tratamento, ao passo que animais terminados em pastagem precisaram ser tratados quatro vezes e, ainda assim, apresentaram taxa de mortalidade de $8 \%$ contra $2 \%$ nos confinados. ${ }^{(27)}$

Ganhos de peso de $175 \mathrm{~g} /$ dia entre animais confinados e semiconfinados, semelhantes aos obtidos neste estudo, foram observados por Carvalho et al. ${ }^{(30)}$ no Rio Grande do Sul em cordeiros Texel terminados em pasto de Tifton-85, recebendo $2 \%$ do mesmo concentrado oferecido aos animais confinados na proporção 40:60 de feno de tifton-85:concentrado. Os autores não descrevem o controle da verminose, mas os animais foram tratados quando necessário. Cordeiras $1 / 2$ Dorset $1 / 2$ Santa Inês terminadas em Capim Coast Cross (Cynodon dactylon L. Pers), suplementadas com 1,5\% do peso vivo e tratadas quando OPG era superior a 500, também não mostraram diferenças no ganho de peso (148 g/dia) quando comparadas com cordeiras confinadas recebendo $4 \%$ do peso vivo de ração completa. ${ }^{(31)}$

Neste estudo, o grau de parasitismo (OPG) nos animais mantidos em pastagem permaneceu baixo, sem necessidade de tratamento, devido ao fato de iniciarem a terminação com OPG muito baixo, como pela pastagem estar vedada e descontaminada pelo longo período sem pastejo com ovinos e ainda, ao período de terminação relativamente curto (Figura 2). Segundo Otto et al., ${ }^{(32)}$ cordeiros terminados a pasto e everminados no início da terminação tiveram o mesmo desempenho que os confinados, porém, se a terminação tivesse uma duração maior, eles poderiam ter desempenho menor devido à infecção elevada que apresentaram ao final do experimento.

Neste estudo, os cordeiros suplementados durante o aleitamento estavam com média de OPG inferior ao dos não suplementados na coleta realizada antes do desmame (5700 vs. 6712) e na segunda das quatro coletas realizadas pós-desmame (102 vs. 339). A média durante o período de terminação foi $322 \pm 1039$ nos cordeiros semiconfinados e $187 \pm 385$ nos confinados (Figura 3 ). 


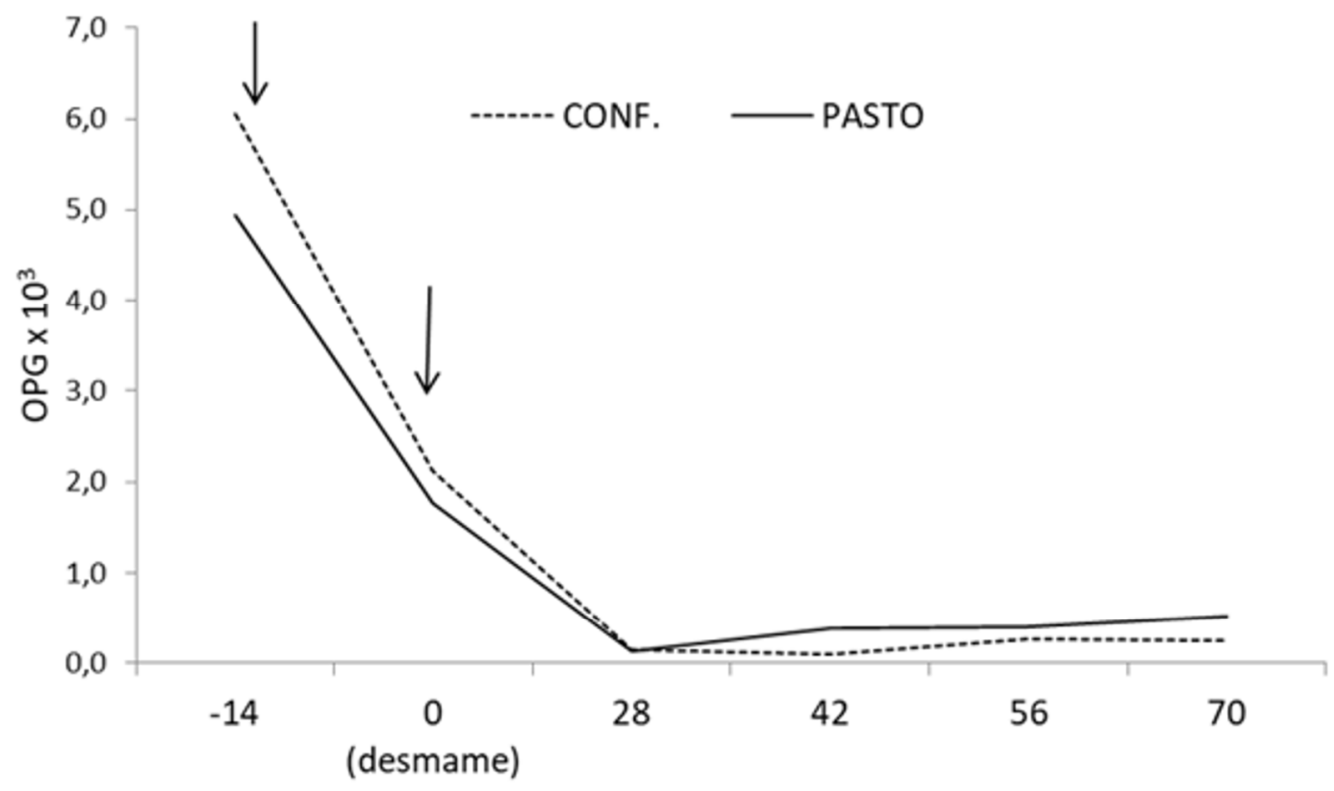

Figura 3. Médias de OPG em cordeiro(a)s terminados em pasto e em confinamento. Todos os animais foram tratados com triclorfon no dia -14 e com levamisol e closantel no desmame.

Os tratamentos anti-helmínticos realizados no dia -14 e no desmame reduziram a média de OPG dos cordeiros para próximo de 100. Como esperado, os animais confinados permaneceram com níveis de OPG baixos até o final, e os semiconfinados mostraram aumento na infecção, mas sem necessidade de tratamentos anti-helmínticos e sem prejuízos no seu desempenho (Figuras 2 e 3).

Nas coproculturas, as percentagens médias de larvas infectantes para Haemonchus, Cooperia e Trichostrongylus foram $96 \%, 3 \%$ e $1 \%$ no lote confinado e $99 \%, 1 \%$ e $1 \%$ no lote semiconfinado.

A ausência de mortalidade nos animais semiconfinados e os ganhos de peso similares nos dois sistemas são indicativos da viabilidade técnica da terminação de cordeiros em pastagens tropicais e, portanto, sistemas de terminação com menos investimentos e maior retorno econômico. O diferimento da pastagem por um período de 150 dias antes do desmame e seu pastejo periódico por bovinos adultos para manter a altura e a qualidade do pasto proporcionaram ganho de peso semelhante ao dos cordeiros confinados recebendo a mesma suplementação.

Durante o aleitamento, os cordeiros suplementados consumiram $1.400 \mathrm{~kg}$ de ração, pesando ao desmame, em média, 2,08 kg a mais do que os não suplementados, sendo 1,58 kg para fêmeas e 2,58 $\mathrm{kg}$ para machos. Tendo em conta uma hora por dia para tratamento dos animais ao custo de $\mathrm{R} \$ 43,90 /$ dia, $\mathrm{R} \$ 500,00$ para construção do cocho privativo com vida útil de cinco anos e valor da ração a $\mathrm{R} \$ 0,60 / \mathrm{kg}$, o custo adicional da suplementação privativa foi de R $\$ 1.362,54$.

Considerando o valor de venda de cordeiros desmamados em $\mathrm{R} \$ 5,00$ por $\mathrm{kg}$ de peso vivo, o uso da ração privativa resultou em relação benefício/custo desfavorável (menor que 1) de 0,98 e 0,60 para os machos e fêmeas, respectivamente, sendo essa prática economicamente inviável para os coeficientes técnicos e relações de preços considerados no presente estudo. Contudo, os cordeiros suplementados na fase de cria continuaram a ganhar mais peso também na fase de terminação, terminando as fêmeas com 2,66 kg e os machos com $3,86 \mathrm{~kg}$ a mais que os não suplementados, resultando uma relação benefício/custo favorável de 1,27 e 1,84, considerando o valor de venda de $\mathrm{R} \$ 6,30$ por $\mathrm{kg}$ de peso vivo de cordeiros terminados.

Análises de viabilidade econômica da terminação de cordeiros têm gerado resultados positivos ou negativos em decorrência dos diferentes componentes considerados nos custos de produção, nas diferenças no desempenho dos animais, variações na receita bruta, etc. Na presente análise, como não 
houve morte de cordeiros e nem diferença significativa no ganho de peso entre os dois sistemas (Figura 4), a receita foi igual e calculada com a média dos pesos obtidos nos cordeiros machos que receberam suplementação privativa no aleitamento (Tabela 2).

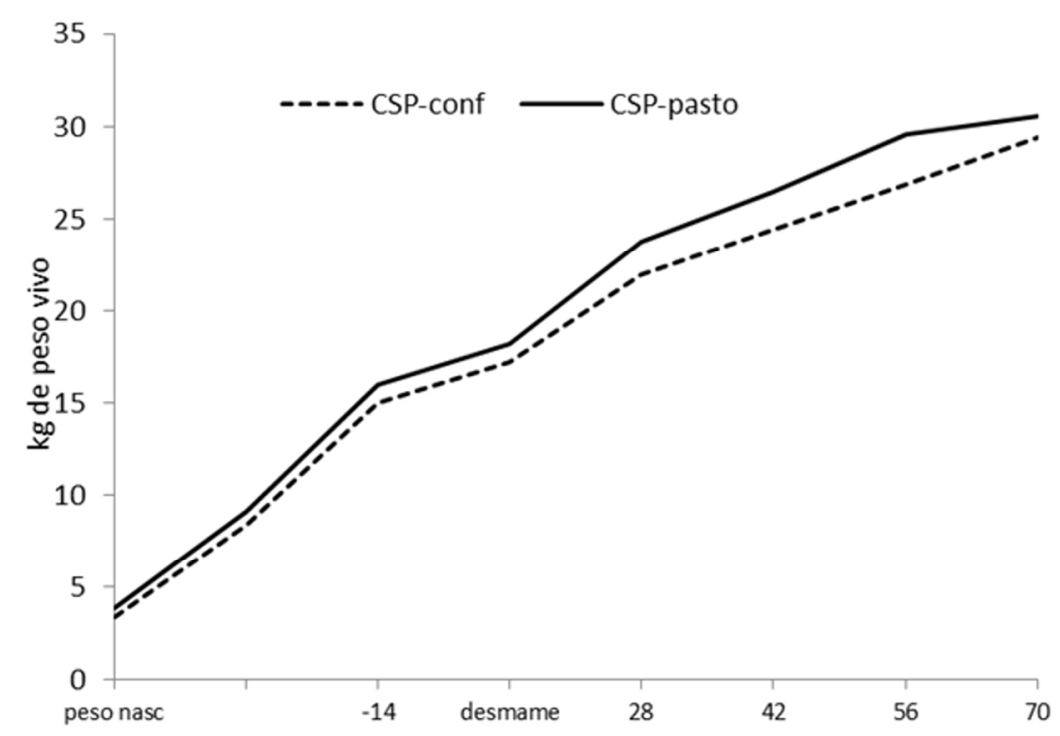

Figura 4. Peso de cordeiros machos do grupo racial Pantaneiro terminados em confinamento (conf) e semiconfinamento (pasto) com suplementação privativa (CSP) durante o aleitamento.

O custo total de produção do quilograma de peso vivo foi de $\mathrm{R} \$ 5,78$ para os cordeiros confinados e de $\mathrm{R} \$ 5,07$ para os semiconfinados, diante de um preço recebido de $\mathrm{R} \$ 6,30$ por $\mathrm{kg}$ de peso vivo. Isto significa que a receita total foi capaz de cobrir a íntegra do custo de produção, sem o pró-labore ao produtor. Para a escala considerada (400 animais abatidos/ano, explorando áreas de 7 ha no semiconfinamento e de 0,06 ha no confinamento), o lucro anual foi de R\$14.819,81 e de R\$6.276,35, respectivamente. Embora o comércio de carcaças seja incipiente no Estado, para obter a mesma receita da comercialização calculada em kg de peso vivo, o valor por $\mathrm{kg}$ de carcaça teria de ser de $\mathrm{R} \$ 13,70$, quando considerado um rendimento de carcaça de $46 \%$.

Os gastos com alimentação foram os mais relevantes depois da compra dos cordeiros desmamados, correspondendo a $20,8 \%$ e $11,9 \%$ do custo total no confinamento e no semiconfinamento. O preço do concentrado proteico está sujeito a variações anuais e sazonais, e um aumento de $30 \%$ no seu custo teria impacto negativo nos lucros de $34,3 \%$ e $14,5 \%$, respectivamente. Por outro lado, uma diminuição de $30 \%$ no seu custo acarretaria lucros superiores nessa mesma proporção nos dois sistemas. No confinamento, a silagem correspondeu a $11 \%$ dos custos totais de produção, e um aumento de $30 \%$ em seu custo acarretaria uma queda de 33\% no lucro desse sistema. Um aumento simultâneo de $30 \%$ no custo do concentrado e de $30 \%$ no custo da silagem impactaria negativamente em $67 \%$ os lucros no sistema confinamento e em $15 \%$ no semiconfinamento.

Supondo um aumento da demanda por carne de cordeiro, e consequente elevação de $20 \%$ no preço, hipótese plausível diante da falta de tradição no consumo dessa carne em expressiva parcela do território brasileiro, os lucros para os sistemas seriam de $\mathrm{R} \$ 20.822,42$ e $\mathrm{R} \$ 29.365,87$, representando acréscimos de $98,1 \%$ e $231,7 \%$ para o confinamento e o semiconfinamento, respectivamente.

Em cordeiras $1 / 2$ Dorset $1 / 2$ Santa Inês, Santello et al. ${ }^{(31)}$ obtiveram receita superior às despesas e, da mesma forma que no presente trabalho, a renda líquida foi maior nas cordeiras terminadas em capim Coast Cross (Cynodon dactylon L. Pers), suplementadas com 1,5\% do peso vivo, em relação às cordeiras terminadas em confinamento recebendo $4 \%$ de ração. Situação inversa, com custo de produção maior que a receita, 
foi observada em cordeiros confinados no Paraná, ${ }^{(27)}$ na região da Campanha Gaúcha ${ }^{(33)}$ e no Mato Grosso do $\mathrm{Sul}^{(34)}$.

Tabela 2. Desempenho animal e indicadores econômicos da terminação de cordeiros confinados ou semiconfinados em pastagem diferida

\begin{tabular}{|c|c|c|}
\hline Desempenho dos cordeiros & Confinamento & Semiconfinamento \\
\hline Peso à desmama $(\mathrm{kg})$ & 17,7 & 17,7 \\
\hline Peso vivo final (kg) & 30,2 & 30,2 \\
\hline $\mathrm{GMD}(\mathrm{g} / \mathrm{dia})$ & 188 & 188 \\
\hline Ganho total (kg) & 12,7 & 12,7 \\
\hline Duração da terminação (dias) & 66 & 66 \\
\hline Idade de abate (dias) & 143,5 & 144,3 \\
\hline Mortalidade na terminação (\%) & $0 \%$ & $0 \%$ \\
\hline Número de animais abatidos & 400 & 400 \\
\hline Custos, receitas e margens (RS) & Confinamento & Semiconfinamento \\
\hline DESEMBOLSOS & $64.994,09$ & $56.622,28$ \\
\hline Manutenção pastagem & 0,00 & $3.144,46$ \\
\hline Calcário & 0,00 & 510,17 \\
\hline Adubação & 0,00 & $2.634,29$ \\
\hline Cordeiros desmamados & $35.000,00$ & $35.000,00$ \\
\hline Alimentação & $14.518,40$ & $7.286,40$ \\
\hline Silagem & $7.232,00$ & 0,00 \\
\hline Concentrado & $6.969,60$ & $6.969,60$ \\
\hline Sal mineral & 316,80 & 316,80 \\
\hline Assistência técnica & $4.160,64$ & $4.160,64$ \\
\hline Mão de obra & $4.329,92$ & 721,65 \\
\hline Impostos e taxas variáveis & $3.174,25$ & $3.174,25$ \\
\hline Medicamentos e vacinas & $1.600,00$ & $1.600,00$ \\
\hline Vermifugos & 600,00 & 600,00 \\
\hline Vacina polivalente/clostridioses & $1.000,00$ & $1.000,00$ \\
\hline Transporte e fretes & 600,00 & 600,00 \\
\hline Despesas diversas & 600,00 & 400,00 \\
\hline Manut. benfeitorias e equipamentos & $1.010,88$ & 534,88 \\
\hline DEPRECIAÇÕES & $2.119,80$ & $1.119,80$ \\
\hline PRO-LABORE & 0,00 & 0,00 \\
\hline JUROS & $2.587,76$ & $3.416,11$ \\
\hline Juros sobre capital em terra/pasto & 12,50 & $1.440,00$ \\
\hline Juros sobre capital em instal., veic. e equip. & 625,44 & 277,44 \\
\hline Juros sobre capital circulante/desembolsos & $1.949,82$ & $1.698,67$ \\
\hline CUSTO OPERACIONAL & $67.113,89$ & $57.742,08$ \\
\hline CUSTO TOTAL & $69.701,65$ & $61.158,19$ \\
\hline RECEITAS & $75.978,00$ & $75.978,00$ \\
\hline Margem bruta & $10.983,92$ & $19.355,72$ \\
\hline Margem operacional & $8.864,12$ & $18.235,92$ \\
\hline Lucro & $6.276,35$ & $14.819,81$ \\
\hline Custo operacional ( $\mathrm{R} \$ \mathrm{~kg}$ vivo produzido) & 5,56 & 4,79 \\
\hline Custo total (RS/kg vivo produzido) & 5,78 & 5,07 \\
\hline Preço recebido ( $\mathrm{R} \$ / \mathrm{kg}$ vivo produzido) & 6,30 & 6,30 \\
\hline
\end{tabular}


O semiconfinamento, em decorrência do desempenho similar em ganho de peso e ausência de mortalidade, foi economicamente melhor. Contudo, diferenças no desempenho animal e nos índices de mortalidade causadas pela verminose podem tornar o sistema de terminação em pasto menos eficiente e/ou inviável. Índices de mortalidade de $8 \%$ a $16 \%$ em animais terminados em pasto e de $2 \%$ a $8 \%$ em animais confinados, causados principalmente pela verminose, têm sido observados. $^{(4,25,27)}$ Em um cenário de $10 \%$ de mortalidade no semiconfinamento, o custo total por $\mathrm{kg}$ de peso vivo aumentaria de $\mathrm{R} \$ 5,07$ para $\mathrm{R} \$ 5,60$, com o lucro reduzindo-se a praticamente à metade.

Cordeiros terminados em Cynodon dactylon ou confinados com ração contendo os mesmos teores de PB e nutrientes digestíveis totais da pastagem mostraram que tanto a terminação em confinamento como em pasto foram economicamente viáveis e com custos de produção próximos; por outro lado, os animais confinados apresentaram maior retorno econômico, dada a mortalidade quatro vezes superior observada nos animais terminados em pasto. ${ }^{(29)} \mathrm{Em}$ razão do risco associado à mortalidade elevada, bem como ao baixo ganho de peso nos animais terminados a pasto, o confinamento é recomendado caso não haja pastagens "limpas" de larvas dos nematódeos ${ }^{(4)}$.

\section{Conclusões}

O diferimento da pastagem de Brachiaria brizantha pelo período de 150 dias controla com eficiência a verminose gastrintestinal e permite terminar cordeiros em pastagem sem o uso de anti-helmínticos; cordeiros confinados com silagem de sorgo ou semiconfinados em pastagem de braquiária diferida, arraçoados com a mesma suplementação proteica, têm ganhos de peso semelhantes;

a suplementação privativa durante o aleitamento aumenta o ganho de peso dos cordeiros até a desmama e na terminação, com retorno econômico favorável na fase de terminação;

no confinamento, o custo com a alimentação e a mão de obra representa mais que o dobro do valor gasto no semiconfinamento.

\section{Agradecimentos}

Os autores agradecem a Fundação de Apoio ao Desenvolvimento do Ensino, Ciência e Tecnologia do Estado de Mato Grosso do Sul (FUNDECT) pelo apoio financeiro ao Prof. Iran Borges, pela consultoria na formulação das dietas, e aos técnicos agrícolas e laboratoristas Marco Antônio da Silva, Marcos Antônio Madureira e Ronaldo Luiz da Silva pelos trabalhos de campo e laboratório.

\section{Referências}

1. Carneiro R del C, Seno MCZ, Rodrigues CFC, Leinz FF, Bianchini D. Study of helmintic infection in Suffolk lambs submitted to two systems of finished. Semina, Ciências Agrarias. 2006; 27(3): 489-496.

2. Siqueira ER. Cria e recria de cordeiros em confinamento. In: Nutrição de ovinos. Jaboticabal: FUNEPFCAJ-UNESP, 1996. p. 175-212.

3. Echevarria FAM. Doenças parasitárias de ovinos e seu controle. In: SIMPOSIO PARANAENSE DE OVINOCULTURA, 3., 1988, Guarapuava. Anais... Londrina: IAPAR, 1988, p. 46-47.

4. Siqueira ER, Amarante AFT, Fernandes S. Estudo comparativo da recria de cordeiros em confinamento e 
pastagem. Revista de Veterinária e Zootecnia. 1993; 5: 17-28.

5. Amarante AFT. Atualidades no controle das endoparasitoses ovinas. In: SIMPÓSIO PAULISTA DE OVINOCULTURA, 4., 1995, Campinas. Anais... Campinas: SAA/CATI, 1995. p. 33-47.

06. Ortolani EL. Efeitos de vários anti-helmínticos avermectínicos sobre o parasitismo experimental de cordeiros parasitados com Haemonchus contortus. A Hora Veterinária. 1995; 88: 21-24.

7. Sczesny-Moraes EA, Bianchin I, Silva KF, Catto JB, Honer MR, Paiva F. Resistência anti-helmíntica de nematóides gastrintestinais em ovinos, Mato Grosso do Sul. Pesquisa Veterinária Brasileira. 2010; 30(3): 229236.

8. Amarante AFT. Controle das Helmintoses Gastrintestinais dos Ovinos e Caprinos. http://www.ascco.com.br/ascco/arquivos not/38/Controle\%20helmintose.pdf em 27.09.2011.

9. Catto JB. Longevidade de larvas infectantes de nematódeos gastrintestinais de bovinos no pantanal matogrossense. Pesquisa Agropecuária Brasileira. 1987; 22(8): 847-854.

10. Souza P, Bellato V, Sartor AA, Ramos Cli. Período para desinfestação das pastagens por larvas de nematóides gastrintestinais de ovinos, em condições naturais nos campos de Lages, SC. Revista Brasileira Parasitologia Veterinária. 2000; 9(2); 159-164.

11. Gordon HMCL, Whitlock A.V. A new technique for counting nematode eggs in sheep feces. Journal Council Scientific Industry Research Australia, v. 12, p. 50-52, 1939.

12. Keith RK. The differentiation on the infective larvae of some common nematode parasites of cattle. Australian Journal of Zoology , v. 1, n. 2, p. 223-235, 1953.

13. SAS Institute Inc. SAS OnlineDOC® 9.3. Cary, NC:SAS Institute Inc., 2014.

14. Perrin RK, Wikelmann DL, Moscardi ER, Anderson JR. Formulación de recomendaciones a partir de datos agronômicos : un manual metodológico de evaluación económica. México: Centro Internacional de Mejoramento de Maiz y Trigo, 1985. 56p. (Folheto de Información, 27)

15. Barros NN, Vasconcelos VR, Wander A, Araujo MRA. Eficiência bioeconômica de cordeiros F1 Dorper x Santa Inês para produção de carne. Pesquisa Agropecuária Brasileira. 2005; 40(8); 825-831.

16. Silva FLR, Araújo AM. Características de reprodução e de crescimento de ovinos mestiços Santa Inês, no Ceará. Revista Brasileira de Zootecnia 2000; 29: 1712-1720.

17. Sampaio AAm, Brito RM, Routman KS. Utilização de $\mathrm{NaCl}$ no suplemento com alternativa de viabilizar o creep feeding. In: REUNIÃO ANUAL DA SOCIEDADE 673 (C) 2008 Sociedade Brasileira de Zootecnia.

18. Neres MA, Garcia CA, Monteiro ALG, Costa C, Silveira AC, Rosa GJM. Níveis de feno de alfafa e forma física da ração no desempenho de cordeiros em creep feeding. Revista Brasileira de Zootecnia. 2001; 30(3): 941-947.

19. Ribeiro TMD, Monteiro ALG, Prado OR, Natel AS, Salgado JA, Piazzetta HL, et al. Desempenho animal e características das carcaças de cordeiros em quatro sistemas de produção. Revista Brasileira de Saúde e Produção Animal. 2009; 10(2); 366-378.

20. Poli CHEC, Monteiro ALG, Barros CS, Moraes A, Fernandes MAM, Piazzetta HVL. Produção de ovinos de corte em quatro sistemas de produção. Revista Brasileira de Zootecnia. 2008; 37(4): 666-673.

21. Vargas Junior FM. Avaliação econômica e desempenho de cordeiros nativos de Mato Grosso do Sul em confinamento. REUNIÃO ANUAL DA SOCIEDADE BRASILEIRA DE ZOOTECNIA, 45. Lavras. Anais... Lavras: Sociedade Brasileira de Zootecnia CDROM. 2008.

22. Mora NHAP. Desempenho produtivo, econômico e características de carcaça de cordeiras pantaneiras. Universidade Estadual de Maringá, 2013, 29 f. : il.,fig. Tabs.

23. Oliveira MA, Silva Filho AS, Mousquer CJ, Mexia AA, Araújo FE, Takamura AE, et al. Desempenho e 
lucratividade de cordeiros mestiços santa Inês x pantaneiro em pastejo suplementado com concentrado. Revista Brasileira de Higiene e Sanidade Animal. 2014; 8 (1), 222-236

24. Tonetto CJ, Pires CC, Muller L, Rocha MG, Silva JHS, Cardoso AR, et al. Ganho de peso e características da carcaça de cordeiros terminados em pastagem natural suplementada, pastagem cultivada de azevém (Lolium multiflorum Lam.) e confinamento. Revista Brasileira de Zootecnia. 2004; 33(1): 225-233.

25. McClure KE, Van Keuren RW, Althouse PG. Performance and carcass characteristics of weaned lambs either grazed on orchardgrass, ryegrass, or alfalfa or fed all-concentrate diets in drylot. Journal Animal Science. 1994; 72: 3230-3237.

26. Frescura RBM, Pires CC, Rocha MG, Silva JHS, Muller L. Sistemas de alimentação na produção de cordeiros para abate aos $28 \mathrm{~kg}$. Revista Brasileira de Zootecnia. 2005; 34(4): 1267-1277.

27. Barros, CS, Monteiro ALG, Poli CHEC, Dittrich JR, Canziani, JRF, Fernandes MAM. Rentabilidade da produção de ovinos de corte em pastagem e em confinamento. Revista Brasileira de Zootecnia. 2009; 38(11): 2270-2279.

28. Macedo FAF, Siqueira ER, Martins EN. Desempenho de cordeiros Corriedale, puros e mestiços, terminados em pastagem e em confinamento. Arquivo Brasileiro de Medicina Veterinária e Zootecnia. 1999; 51(6): 583-587.

29. Macedo FAF, Siqueira ER, Martins EL. Análise econômica da produção de carne de cordeiros sob dois sistemas de terminação: pastagem e confinamento. Ciência Rural. 2000; 30(4), 677-680.

30. Carvalho S, Brochier MA, Pivato J, Teixeira RC, Kieling R. Ganho de peso, características da carcaça e componentes não-carcaça de cordeiros da raça Texel terminados em diferentes sistemas alimentares. Cienc. Rural. 2007; 37(3): 821-827.

31. Santello GA, Macedo FAF, Mexia AA, Sakaguti ES, Dias FJ, Pereira MF. Características de carcaça e análise do custo de sistemas de produção de cordeiras $1 / 2$ Dorset Santa Inês. Revista Brasileira de Zootecnia. 2006; 35(4): 1852-1859.

32. Otto C, Sá JL, Woehl AH. Estudo econômico da terminação á pasto e em confinamento. Curitiba : Universidade federal do Paraná, 1966. 4p. (Nota Cientifica)

33. Piccoli M, Correa GF, Rohenkohl JE, Tontin IF, Moreira SM, Rossato VM. Viabilidade econômica de um sistema de terminação de cordeiros em confinamento na região da Campanha/RS. Rev. Eletronica em Gestão, Educação e Tecnologia Ambiental. 2013; 11(11): 2493-2505.

34. Souza MR, Vargas Júnior FM, Souza LCF, Talamini E, Camilo FR. Análise econômica do confinamento de cordeiros alimentados com feno de capim piatã e soja in natura ou desativada. Custos e @gronegócio on line v. 10, n. 1 - JanMar - 2014. ISSN 1808-2882 www.custoseagronegocioonline.com.br. 